\title{
Predictors of Ventilator Associated Pneumonia of Neonate in a Neonatal and Paediatric Intensive Care Unit
}

\author{
UZZAL KUMAR GHOSH ${ }^{1}$, MOHAMMAD MONIR HOSSAIN², MAHFUZA SHIRIN², MD. SHAFIUL \\ HOQUE $^{4}$, SHEIKH FARJANA SONIA ${ }^{5}$, TITHI ISLAM ${ }^{6}$
}

\begin{abstract}
Background: Ventilator Associated Pneumonia (VAP) is defined as nosocomial pneumonia develops 48 hours or more after initiation of mechanical ventilation. Hospital acquired infection (HAl) is the second most common infection for the pediatric population. VAP about $20 \%$ of all HAI among patients in NICU \& PICU. Higher mortality and morbidity rate for mechanically ventilated pediatric patients with VAP compared to those without VAP. Few data \& very few researches exist regarding VAP in pediatric patients to identify risk factors of VAP and that might be helpful for preventing VAP. This study was done to find out the predictors of VAP of neonate in Neonatal and Pediatric Intensive Care Unit.

Methodology: A prospective cohort study was carried out in NICU \& PICU of Dhaka Shishu (Children) Hospital, Dhaka. Neonates those not had pneumonia; requiring mechanical ventilation at least 48 hours in the NICU or PICU were taken for this study. Then VAP patients were selected by radiographic changes after 48 hours of intubation. Portable chest $x$-ray was done after 48 hours and as required after initiation of ventilation. Then details history were taken and some relevant investigation were done.

Result: Majority (51.4\%) of the neonates belonged to age group 0-10 days. Male female ratio was 2.8:1. More than half (51.4\%) were of gestational age 34 to $<37$ weeks. Sixty nine point four percent of the neonates had Weight $<2.5 \mathrm{~kg}$. Transferred from other NICU or PICU was found in $34.7 \%$, prolonged mechanical ventilation was found in $40.3 \%$, reintubation were $36.1 \%$, prior antibiotics use were $73.6 \%$, nosocomial infection were $76.4 \%$, oropharyngeal aspiration were $11.1 \%$ and those having VAP were $79.2 \%$. Age group 11-20 days (RR=1.41; 95\% Cl 1.18 to 1.67), gestational age <37 weeks ( $R R=1.48 ; 95 \% \mathrm{Cl} 1.12$ to 1.96$)$, weight $<2.5 \mathrm{~kg}(R R=2.24$; $95 \% \mathrm{Cl} 1.20$ to $4.18 \%$ ), nosocomial infection (RR=3.21; 95\% Cl 1.53 to $6.73 \%$ ), transferred from other NICU \& PICU (RR=1.47; 95\% Cl 1.21 to 1.79), Prolonged Mechanical Ventilation ( $R R=1.50 ; 95 \% \mathrm{Cl} 1.01$ to $2.23 \%$ ) and Reintubation ( $R R=1.48$; 95\% Cl 1.21 to $1.81 \%$ ) were found independent predictors for developing VAP. $P$ value was found statistically significant $(p<0.05)$.

Conclusion: Age group 11-20 days, gestational age $<37$ weeks, weight $<2.5 \mathrm{~kg}$, transferred from other NICU \& PICU, prolonged mechanical ventilation, reintubation and nosocomial infection were regarded as predictors for VAP and those predictors were significantly associated with VAP.
\end{abstract}

Key words: Ventilator Associated Pneumonia, NICU, PICU, Predictors.

1. Registrar, Dr. MR Khan Shishu Hospital \& ICH, Mirpur-2, Dhaka.

2. Professor, Department of Neonatal Medicine and NICU, BICH and Dhaka Shishu (Children) Hospital, Dhaka.

3. Associate Professor, Department of Neonatology, $\mathrm{BICH}$ and Dhaka Shishu (Children) Hospital, Dhaka.

4. Associate Professor, Department of Paediatrics (PICU), $\mathrm{BICH}$ and Dhaka Shishu (Children) Hospital, Dhaka.

5. Assistant Professor, Department of Paediatrics (SCANU), Dr. M R Khan Shishu Hospital \& ICH, Mirpur-2, Dhaka.

6. Consultant Pediatrics, 250 bed Zilla Hospital, Manikgonj.

Correspondence: Dr. Uzzal Kumar Ghosh, Registrar, Department of Paediatrics, Dr. M R Khan Shishu Hospital \& ICH, Mirpur-2, Dhaka. Email: uzzalghosh1987@gmail.com Mobile: +88 01790117535.

Received: 01-09-2018

Accepted: 24-06-2019

\section{Introduction}

Ventilator Associated Pneumonia (VAP) is defined as nosocomial pneumonia develops 48 hours or more after initiation of mechanical ventilation. Hospital acquired pneumonia (HAl) is the second most common infection after bloodstream infection for the pediatric population. VAP accounts for about $20 \%$ of all HAl among patients in pediatric intensive care unit (PICU). Furthermore, some data suggested higher mortality rate for mechanically ventilated pediatric patients with VAP compared to those without VAP. 
Hospital costs and the length of ICU stay were significantly increased for pediatric patients with VAP compared to those without VAP. ${ }^{1}$

The epidemiology, pathogenesis, and outcome of VAP are well described in adults. However, few data exist regarding VAP in pediatric patients. Because of different anatomy, physiology and underlying illnesses from adults, it is important to identify specific prevention for this population in preventing VAP. Till now, there have been very few researches about risk factors of VAP in PICU. However, these results indicated that risk factors were varied or contradictory. Reintubation and transport in from other PICU were independent predictors of VAP. ${ }^{2}$ However, only prior antibiotic therapy was independent predictors of VAP. $^{3}$

Incidence of VAP ranges from $9 \%$ to $70 \%$. Mortality ranges from $13 \%$ to $55 \%$. VAP increases average hospital stay from 6 days to more than 30 days, and also increases costs up to $\$ 50,000$ per hospital stay. ${ }^{4}$

VAP is the second most common Nosocomial infection after urinary tract infection in PICU patients, accounting for $20 \%$ of nosocomial infection in this population. The pneumonia rate was $6-21$ fold higher for patients receiving ventilator support compared to those not requiring mechanical ventilation. Also intubations independently increase the risk of nosocomial pneumonia seven fold. ${ }^{5}$

Langer and co-workers divided VAP into early onset VAP which occurs within 5 days of mechanical ventilation and late onset VAP which develops on equal or more than 5 days after initiation of mechanical ventilation. The importance of segregating VAP into early and late is that, the pathogenesis and microorganisms responsible for these two groups, along with the outcome of these two groups are different, and hence the therapeutic implications also differ. Early onset VAP results from aspiration of endogenous community acquired organisms e.g. S. pneumoniae, $H$. influenzae, and other organisms (aerobic gram negative bacilli). Late onset VAP is more severe and results usually from aspiration of gastric/oropharyngeal secretions, and is caused by potentially drug resistant organisms like methicillin resistant Staphylococcus aureus (MRSA) and Pseudomonas. ${ }^{6}$

When a microorganism is isolated from a blood culture in a patient with pneumonia, that organism is the likely etiological pathogen. Even in complex circumstances, such as nosocomial VAP, if a non pulmonary infection is absent, then a positive blood culture is considered presumptive evidence of an exact etiological diagnosis. ${ }^{7}$

Ventilator Associated Pneumonia (VAP) is one of the leading causes of death among hospital acquired infections. The patient develops a shadow on the lungs, such as patchy opacity, consolidation, cavitation, and/or pneumatoceles, along with fever, leukopenia or leukocytosis and/or new onset of purulent sputum, change in character of sputum, increased respiratory secretions, or increased suctioning requirements. There may also be a new onset of or worsening cough, dyspnea, or tachypnea, associated with rales or bronchial breath sounds, worsening gas exchange $\left(\mathrm{O}_{2}\right.$ desaturations), increased oxygen requirements or increased ventilation demand. ${ }^{6}$

The primary risk factor for the development of VAP is mechanical ventilation and improper care after intubation. Critically ill patients especially intubated patients are at the higher risk of acquiring VAP.

The incidence of VAP ranges from $10-65 \%$ of intubated patients depending on the risk factors. Risk factors were reintubation, age, prior antibiotics, and duration of Intermittent Positive Pressure Ventilation (IPPV). The mortality of VAP ranges from $13 \%$ to 55 $\%$. VAP is commonly caused by antibiotic-resistant nosocomial organisms like Pseudomonas aeruginosa, Eschericha coli, Klebsiella pneumoniae, Acinetobacter species and Staphylococcus species. ${ }^{8}$

CDC guidelines for the prevention of VAP include recommendations for nursing care. One recommendation for staff is to participate in educational interventions since educational interventions can reduce VAP rates. ${ }^{9}$

\section{Methodology}

Prospective cohort study. NICU and PICU of Dhaka Shishu (Children) Hospital, Dhaka from October 2015 to April 2017. Age 0-28 days and neonates required mechanical ventilation at least 48 hours in the NICU or PICU was included in this study. Neonates required mechanical ventilation in the NICU or PICU were taken for this study. Then VAP patients were selected after 48 hours of intubation by radiographic change. Portable chest $x$-ray was done by an expert technician after 48 hours, and as required after initiation of 
mechanical ventilation and follow upto development of Ventilator Associated Pneumonia. Data was collected including demographics, medical history, medical documents, the need for mechanical ventilation, duration of ventilation and previous ICU admission with treatment received. Bacteremia was detected by CBC with PBF, CRP (Haematological scoring system), ${ }^{10,11}$ Blood Culture \& Sensitivity, tracheal aspirate for Culture \& Sensitivity. Under all aseptic precaution blood sample was collected by an expert ICU staff from peripheral accessible vein. Hospital discharge status was noted for all patients.

Statistical analysis were carried out using the Statistical Package for Social Sciences version 23.0 for Windows (SPSS Inc., Chicago, Illinois, USA). The quantitative observations were indicated by frequencies and percentages. Relative risk measurement with $95 \% \mathrm{Cl}$ limit was done for risk factor. $P$ values $<0.05$ were considered as statistically significant.

\section{Results}

More than half $(51.4 \%)$ of the neonates belonged to age group 0-10 days. Males were predominant in this study comprising of $73.6 \%$ and females were $26.4 \%$. Male female ratio was $2.8: 1$ (Table-I).

Table-I

Distribution of the study neonates by sociodemographic variable $(n=72)$

\begin{tabular}{lcc}
\hline $\begin{array}{l}\text { Socio-demographic } \\
\text { variable }\end{array}$ & $\begin{array}{c}\text { Number of } \\
\text { neonates }\end{array}$ & Percentage \\
\hline Age (days) & & \\
$0-10$ & 37 & 51.4 \\
$11-20$ & 20 & 27.8 \\
$21-28$ & 15 & 20.8 \\
Sex & & \\
$\quad$ Male & 53 & 73.6 \\
$\quad$ Female & 19 & 26.4 \\
\hline
\end{tabular}

More than half ( $51.4 \%$ ) neonates were of gestational age 34 to $<37$ weeks. Weight $1.5 \mathrm{~kg}$ to less than 2.5 $\mathrm{kg}$ neonates were found $42(58.3 \%)$. Neonates transferred from other NICU \& PICU were 25(34.7\%). Twenty nine $(40.3 \%)$ neonates had prolonged mechanical ventilation. Twenty six $(36.1 \%)$ neonates had undergone reintubation and $53(73.6 \%)$ neonates used prior antibiotics. More than three fourth $(76.4 \%)$ neonates had nosocomial infection when detected by Hematological scoring system $(62.5 \%)$ and by blood culture (13.9\%) \& sensitivity. Eight $(11.1 \%)$ neonates had oropharyngeal aspiration (Table-II).

Table-II

Distribution of the study neonates by given variables $(n=72)$

\begin{tabular}{lcc}
\hline Variables & No. of neonates & Percentage \\
\hline $\begin{array}{l}\text { Gestational age (weeks) } \\
\quad 28 \text { to }<34\end{array}$ & 3 & 4.2 \\
$\quad 34$ to $<37$ & 37 & 51.4 \\
$\quad \geq 37$ & 32 & 44.4 \\
Admission weight (kg) & & \\
$<1.5$ & 8 & 11.1 \\
1.5 to $<2.5$ & 42 & 58.3 \\
$\geq 2.5$ & 22 & 30.6 \\
Transferred from other & 25 & 34.7 \\
NICU or PICU & & \\
Prolonged mechanical & 29 & 40.3 \\
ventilation ( $\geq 3$ days) & & \\
Reintubation & 26 & 36.1 \\
Prior antibiotic use & 53 & 73.6 \\
Nosocomial infection & 55 & 76.4 \\
$\begin{array}{l}\text { Oropharyngeal aspiration } \\
\text { by tracheal aspirate for C/S }\end{array}$ & 8 & 11.1 \\
\hline
\end{tabular}

$10(13.9 \%)$ neonates had nosocomial infection when detected by blood C/S (Table-III).

Table-III

Nosocomial infection detected by blood C/S ( $n=72)$

\begin{tabular}{lcc}
\hline $\begin{array}{l}\text { Bacteriaemia or } \\
\text { septicaemia by blood C/S }\end{array}$ & $\begin{array}{c}\text { Number of } \\
\text { neonates }\end{array}$ & \\
\hline Positive & 10 & 13.9 \\
Negative & 62 & 86.1 \\
\hline
\end{tabular}

Majority 66(91.67\%) patients had perinatal asphyxia followed by $44(61.1 \%)$ had neonatal sepsis, $36(50.0 \%)$ had preterm LBW and $8(11.1 \%)$ had post surgical case (Table-IV). 
Table-IV

Indication of mechanical ventilation $(n=72)$

\begin{tabular}{lcc}
\hline Indication & $\begin{array}{c}\text { Number of } \\
\text { the neonate }\end{array}$ & Percentage \\
\hline Perinatal asphyxia & 66 & 91.67 \\
Neonatal sepsis & 44 & 61.1 \\
Preterm LBW & 36 & 50.0 \\
Post surgical case & 8 & 11.1 \\
\hline
\end{tabular}

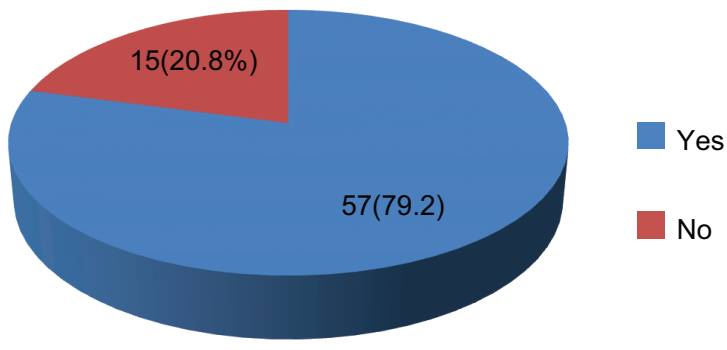

Fifty seven (79.2\%) neonates had VAP (Fig.-1).

Fig. -1 VAP of the study neonates $(n=72)$

Table-V

Relative Risk (RR) measurement shows predictors of VAP

\begin{tabular}{lccc}
\hline Variables & RR & 95\% ClLower- upper & P value \\
\hline Age group 11-20 days & 1.41 & $1.18-1.67$ & $0.004^{*}$ \\
Sex (male) & 1.00 & $0.77-1.31$ & 0.606 \\
Gestational age less than 37 weeks & 1.48 & $1.12-1.96$ & $0.001^{*}$ \\
Weight less than 2.5 kg & 2.24 & $1.20-4.18$ & $0.001^{*}$ \\
Nosocomial infection & 3.21 & $1.53-6.73$ & $0.001^{*}$ \\
Prior antibiotic use & 1.21 & $0.87-1.63$ & 0.155 \\
Transferred from other NICU \& PICU & 1.47 & $1.21-1.79$ & $0.002^{*}$ \\
Prolonged Mechanical Ventilation & 1.50 & $1.01-2.23$ & $0.012^{*}$ \\
Reintubation & 1.48 & $1.21-1.81$ & $0.001^{*}$ \\
Orophryngeal aspiration & 1.12 & $0.84-1.50$ & 0.469 \\
\hline
\end{tabular}

* Significant

Age group $11-20$ days ( $R R=1.41 ; 95 \% \mathrm{Cl} 1.18$ to 1.67 ), gestational age less than 37 weeks $(R R=1.48 ; 95 \%$ $\mathrm{Cl} 1.12$ to 1.96$)$, weight less than $2.5 \mathrm{~kg}(\mathrm{RR}=2.24$; $95 \% \mathrm{Cl} 1.20$ to $4.18 \%$ ), nosocomial infection (RR= $3.21 ; 95 \% \mathrm{Cl} 1.53$ to $6.73 \%$ ), transferred from other NICU \& PICU (RR=1.47; 95\% Cl 1.21 to 1.79$)$, Prolonged Mechanical Ventilation $(\mathrm{RR}=1.50 ; 95 \% \mathrm{Cl}$ 1.01 to $2.23 \%$ ) and Reintubation ( $R R=1.48 ; 95 \% \mathrm{Cl}$ 1.21 to $1.81 \%$ ) were found independent predictors for developing VAP (Table-V).

\section{Discussion}

This prospective cohort study was carried out in NICU and PICU of Dhaka Shishu (Children) Hospital, Dhaka. VAP patients were selected after 48 hours of intubation by radiographic change. Portable chest $\mathrm{x}-$ ray was done by an expert technician after 48 hours and as required after initiation of mechanical ventilation.
In this study it was observed that more than half (51.4\%) neonates belonged to age group 0-10 days develops VAP. The study showed postnatal age on admission was found to be $3.26 \pm 4.0$ days. ${ }^{6}$

In our study it was observed that male were predominant in this study which comprised $73.6 \%$ and females were $26.4 \%$. Male female ratio was 2.8:1. In comparison to other study $73.0 \%$ were males. ${ }^{6}$ Another study showed a majority of $58.0 \%$ were male babies. ${ }^{2}$ Once reported that $50.2 \%$ patients were male and $49.8 \%$ were female. ${ }^{12}$

In this series it was observed that more than half (51.4\%) neonates were gestational age 34 to $<37$ weeks. Similar result showed that $56.67 \%$ prematurity (<37 weeks). ${ }^{6}$ Mean gestational age was $27.1 \pm 2.3$ weeks in the VAP group. ${ }^{13}$ 
Regarding admission weight in this study, weight less than $2.5 \mathrm{~kg}$ neonates were $69.4 \%$ and weight equal or more than $2.5 \mathrm{~kg}$ neonates were $30.6 \%$ among neonates. In the cross sectional survey by VAP rates were highest for the $1,001 \mathrm{gm}$ to $1,500 \mathrm{gm} .{ }^{5}$ Very low birth weight (birth weight $<1.5 \mathrm{~kg}$ ) were found to be $33.33 \% .{ }^{6}$ Another reported that most of the (8677) very low birth weight infants from 52 neonatology departments in Germany developed VAP. ${ }^{14}$

In this study it was observed that neonates transferred from other NICU \& PICU were 25(34.7\%) developed VAP. Neonates in isolation unit who were transferred from a neonatal intensive care unit (NICU) developed bacterial infections. ${ }^{15}$

In our study it was observed that 29(40.3\%) neonates had prolonged mechanical ventilation. Patients with nosocomial pneumonia after prolonged mechanical ventilation were $63.6 \%{ }^{5}$

In this study it was observed that $26(36.1 \%)$ neonates had reintubation. Reintubation was found in $60.0 \%$ and also $13.7 \%$ patients. ${ }^{6,2}$

In our study it was observed that $53(73.6 \%$ ) neonates having prior use of antibiotics developed VAP. A prospective cohort study at an academic tertiary care center performed in a PICU found that over half $(56.6 \%)$ of all patients receiving antibiotics developed VAP. ${ }^{16}$

Regarding nosocomial infection of the neonates, it was observed that $55(76.4 \%)$ neonates had nosocomial infection. Nosocomial infection was found as a risk factor not only for VAP, but also for most of the hospital admitted patients found in many studies. But exact percentages were not mentioned for developing VAP. Surveillance studies of nosocomial infections in NICU patients indicate that pneumonia comprises 6.8 to $32.3 \%$ of nosocomial infections. ${ }^{17}$

In this study shows tracheal aspirate C/S positive was found in $8(11.1 \%)$ cases. Among them were Acinetobacter (50\%) (Resistance to all antibiotic; some times sensitive to Colistin sulphate, Sporicidin$B$ and intermediately sensitive to Cotrimoxazole, Netilmicin), Stenotrophomonas maltophilia (12.5\%) (Sensitive to Minocycline), Pseudomonas sp. (37.5\%) (Sensitive to Netilmicin and Piperacillin). Isolation of multiple organisms from tracheal aspirates developed VAP in extremely preterm neonates. Most of the tracheal isolates from patients with VAP grew polymicrobial cultures; the organisms most commonly isolated included Staphylococcus aureus (23\%), Pseudomonas aeruginosa (38.4\%), Enterobactersp. (38.4\%), and Klebsiella sp. (23\%). ${ }^{12}$ The most common pathogens isolated in the neonatal population are Pseudomonas aeruginosa and Staphylococcus aureus. ${ }^{18}$ However, isolation of other microorganisms such as Klebsiella pneumoniae and Escherichia coli has also been reported. ${ }^{6,19}$

In this study blood C/S positive was found in $10(13.9 \%)$ cases. Eleven percent blood culture positive by another authors which is similar to our study. ${ }^{11}$ We found common organisms like Staphylococcus aureus (20\%) (Sensitive to Flucloxacillin), Acinetobacter (40\%) (Resistance to all antibiotic; some times sensitive to Amikacin, Netilmicin), Klebshella pneumoniae (20\%) (Resistance to all antibiotic occasionally intermediately sensitive to Azythromicin), Coagulase negative Staphylococci (20\%) (Sensitive to Cotrimoxazole, Vancomycin and intermediately sensitive to Gentamicin). Commonest microorganisms isolated throughout the study were gramnegative bacteria (95.5\%) cases and particularly Klebsilla pneumonia (83.4\%) cases. ${ }^{20}$ VAP is commonly caused by antibiotic-resistant nosocomial organisms like Pseudomonas aeruginosa, Eschericha coli, Klebsiella pneumoniae, Acinetobacter sp. and Staphylococcus species. ${ }^{8}$

In our study it was observed that $57(79.2 \%$ ) neonates had VAP. Another study showed that VAP developed in 30 out of 98 neonates ( $30.6 \%$ VAP rate). ${ }^{6}$

This study showed that age group 11-20 days ( $R R=1.41 ; 95 \% \mathrm{Cl} 1.18$ to 1.67$)$, gestational age less than 37 weeks $(R R=1.48 ; 95 \% \mathrm{Cl} 1.12$ to 1.96$)$, weight less than $2.5 \mathrm{~kg}(\mathrm{RR}=2.24 ; 95 \% \mathrm{Cl} 1.20$ to $4.18 \%$ ), nosocomial infection ( $R R=3.21 ; 95 \% \mathrm{Cl} 1.53$ to $6.73 \%$ ), transferred from other NICU \& PICU $(\mathrm{RR}=1.47 ; 95 \% \mathrm{Cl} 1.21$ to 1.79$)$, Prolonged Mechanical Ventilation $(R R=1.50 ; 95 \% \mathrm{Cl} 1.01$ to $2.23 \%$ ) and Reintubation ( $R R=1.48 ; 95 \% \mathrm{Cl} 1.21$ to $1.81 \%$ ) were found independent predictors for developing VAP. $P$ value were found statistically significant $(p<0.05)$. Among many risk factors, these factors had statistical significances. Risk factors of VAP and its value of OR were as follows: reintubation or self-extubation (OR $=3.16$; $95 \% \mathrm{Cl}$ : $2.10-4.74$ ), bloodstream infection (OR $=4.42 ; 95 \% \mathrm{Cl}$ : $2.12-9.22$ ) and prior antibiotic therapy $(\mathrm{OR}=2.89 ; 95 \% \mathrm{Cl}: 1.41$ 5.94). ${ }^{1}$ 
Several prospective cohort studies described risk factors for pediatric VAP. In a prospective cohort study at a tertiary care center; transfer out of the PICU (OR, $8.90 ; 95 \% \mathrm{Cl}, 3.82$ to 20.74 ), and reintubation (OR, $2.71 ; 95 \% \mathrm{Cl}, 1.18$ to 6.21 ) were all independent predictors of pediatric VAP. ${ }^{2}$ The same also found that primary blood stream infections were associated with the development of VAP. Another prospective cohort study identified prior antibiotic use (OR, 2.45; 95\% Cl: 1.112 to 5.405 ) as being independent predictor of pediatric VAP. ${ }^{3}$ Several factors identified associated with increased risk of developing VAP: reintubation (OR, 4.95 ; $95 \% \mathrm{Cl}: 3.48$ to 7.04 ; $\mathrm{P}=$ $0.000012)$ and mechanical ventilation for $>3$ days (OR, 1.17; 95\% Cl: 1.15 to $1.19 ; \mathrm{P}=0.015) .{ }^{21}$

In the current study, common indication of ventilation were perinatal asphyxia, neonatal sepsis, preterm LBW and some post operative surgical cases. Recovery or discharge with advise were $7(9.7 \%)$, discharge with risk bond were $27(37.5 \%)$ due to financial problem and mortality were $38(52.8 \%)$. Another study found that $13-55 \%$ mortality. ${ }^{8}$ Although among the mortality of VAP some cases were associated with some comorbidities.

\section{Conclusion}

Age group 11-20 days, gestational age less than 37 weeks, weight less than $2.5 \mathrm{~kg}$, transferred from other NICU \& PICU, prolonged mechanical ventilation, reintubation and nosocomial infection were regarded as predictors for Ventilator Associated Pneumonia and those predictors were significantly associated with developing Ventilator Associated Pneumonia.

\section{References}

1. Liu B, Li S, Zhang S, Xu P, Zhang X, Zhang Y et al. Risk factors of ventilator-associated pneumonia in pediatric intensive care unit: a systematic review and meta-analysis. J Thorac Dis 2013; 5: 525-31.

2. Elward AM, Warren DK, Fraser VJ. Ventilatorassociated pneumonia in pediatric intensive care unit patients: risk factors and outcomes. Pediatrics 2002; 109: 758-64.

3. Almuneef M, Memish ZA, Balkhy $\mathrm{HH}$, Alalem $\mathrm{H}$, Abutaleb A. Ventilator-associated pneumonia in a pediatric intensive care unit in Saudi Arabia: a 30 -month prospective surveillance. Infect Control Hosp Epidemiol 2004; 25: 753-8.
4. World Health Organization. Ventilatorassociated pneumonia source of the highest morbidity and mortality of all hospital acquired infections. http://www. haiwatch.com/VAP.aspx. on 25 August 2010.

5. Foglia E, Meier MD, Elward A. VentilatorAssociated Pneumonia in Neonatal and Pediatric Intensive Care Unit Patients. Clin Microbiol Rev 2007; 20: 409-25.

6. Tripathi S, Malik GK, Jain A, Kohli N. Study of ventilator-associated pneumonia in neonatal intensive care unit: charecterisitcs, risk factors and outcome. Internet Journal of Medical Update 2010; 5(1): 12-9.

7. Luna CM, Videla A, Mattera J, Vay C, Famiglietti $A$, Vujacich $P$ et al. Blood cultures have limited value in predicting severity of illness and as a diagnostic tool in ventilator-associated pneumonia. Chest 1999; 116(4): 1075-84.

8. Ozkurt S, Sungurtekin $\mathrm{H}$, Aydemir $\mathrm{N}$, Atalay $\mathrm{H}$, Zencir M, Baser $S$ et al. Ventilator-Assosiated Pneumonia: Retrospective Results In An Intensive Care Unit. The Internet Journal of Gastroenterology 2006; 5(2): 748-9.

9. Salahuddin N, Zafar A, Sukhyani L, Rahim S, Noor M, Hussain $\mathrm{K}$ et al. Reducing vrentiltor associated pneumonia rates through a staff education programme. Journal of Hospital Infection 2006; 57(3): 223-7.

10. Rodwell RL, Leslie AL, Tudehope DI. Early diagnosis of neonatal sepsis using a hematologic scoring system. J Pediatr 1988; 112(5): 761-7.

11. Yusuf MM, Aiam J, Hussain MM, Chowdhury MAK. Evaluation of haematological scoring system (HSS) for early diagnosis of neonatal sepsis. Dhaka Shishu (Children) Hospital Journal 2014; 30(1): 14-9.

12. Apisarnthanarak $A$, Holzmann-Pazgal $G$, Hamvas A, Olsen MA, Fraser VJ. VentilatorAssociated Pneumonia in Extremely Preterm Neonates in a Neonatal Intensive Care Unit: Characteristics, Risk Factors, and Outcomes. Pediatrics 2003; 112: 1283-9.

13. Lee PL, Lee WT, Chen HL. VentilatorAssociated Pneumonia in Low Birth Weight Neonates at a Neonatal Intensive Care Unit: A 
Retrospective Observational Study. Pediatrics and Neonatology 2017; 58: 16-21.

14. Geffers C, Baerwolff S, Schwab F, Gastmeier $P$. Incidence of healthcare-associated infections in high-risk neonates: results from the German surveillance system for very-low-birth weight infants. J Hosp Infect 2008; 68: 214-21.

15. Navarro LR, Pekelharing-Berghuis $M$, de Waal WJ, Thijsen SF. Bacterial colonization patterns in neonates transferred from neonatal intensive care units. Int J Hyg Environ Health 2011; 214: 167-71.

16. Fischer JE, Ramser M, Fanconi S. Use of antibiotics in pediatric intensive care and potential savings. Intensive Care Med 2000; 26 : 959-66.

17. Drews MB, Ludwig AC, Leititis JU, Daschner FD. Low birth weight and nosocomial infection of neonates in a neonatal intensive care unit. J. Hosp. Infect. 1995; 30: 65-72.
18. Cernada M, Aguar M, Brugada M. Ventilatorassociated pneumonia in newborn infants diagnosed with an invasive bronchoalveolar lavage technique: a prospective observational study. Pediatr Crit Care Med 2013; 14: 55-61.

19. Afjeh SA, Sabzehei MK, Karimi A, Shiva F, Shamshiri AR. Surveillance of ventilatorassociated pneumonia in a neonatal intensive care unit: characteristics, risk factors and outcome. Arch Iran Med 2012; 15: 567-71.

20. Azab SFA, Sherbiny HS, Saleh SH, Elsaeed WF, Elshafiey MM, Siam AG, et al. Reducing ventilator associated pneumonia in neonatal intensive care unit using "VAP prevention Bundle": a cohort study. BMC Infectious Diseases 2015; 15: 314.

21. Torres A, Aznar R, Gatell JM, Jimenez P, Gonzalez J, Ferrer A et al. Incidence, risk, and prognosis factors of nosocomial pneumonia in mechanically ventilated patients. Am Rev Respir Dis. 1990; 142: 523-8. 